\title{
Fostering Students' Initial Understanding of Area Measurement through the Idea of Consistency and Inverse Relationship of Unit
}

\author{
Febrian \\ Department of Mathematics Education \\ Maritime University of Raja Ali Haji \\ Tanjungpinang, Indonesia \\ febrian@umrah.ac.id, febrianfebz@gmail.com
}

\begin{abstract}
This study examined the way of helping fifteenthird grade students of the elementary school to understand the area measurement through the area unit. Two main concepts of area unit discussed in this study were the idea of unit consistency and the inverse relationship between the number of predetermined units and unit size itself. The approach of the study was designed to research on area measurement by using Indonesian Realistic Mathematics Education (IRME). Photo frame was used as the context of learning activities. Series of comparing-measuring tasks were set over the learning process. The result indicates that the context of photo frame in learning activities could trigger the need for the tool (unit) to measure the area through comparing task. On the other hand, the students could develop the idea of identical units to fairly compare some two-dimensional regions through the measuring task on the photo frame. The result also suggests that the students developed the idea of the inverse relationship between the number of units and the size of the predetermined unit during the covering activity.
\end{abstract}

Keywords-area measurement; identical units; inverse relationship; unit consistency

\section{INTRODUCTION}

One of the most commonly used forms of measurement that is closely connected to real-world applications is area measurement. This measurement becomes important since the basic concept of area measurement itself has relation with other mathematical ideas [1]. Some mathematical ideas that are related to the area are multiplications, enlargement, and similarity [2]. For its importance, the area measurement is contained within Indonesia curriculum starting from the third grade of elementary school.

However, research in the field of education often reveals a poor understanding of the process used for the area measurement of plan figure [3]. The common strategy the students perform while figuring out the area of the region is by using the rules. First, these students measure the length and the width of plan. Secondly, they simply add or multiply those lengths and treat the product or the sum as the area of plan. Unfortunately, there is no understanding of why the students doing so. The other strategy is that the students treat the length as a space-filling attribute [4]. They report the result they obtain as the area. At least there are two kinds of issues that can be derived from this situation [5]. Firstly, students do not know yet what to measure on the region. Secondly, students do not know yet how to measure the area of the region. In learning process of area measurement, students are guided to lengthtimes-width formula directly. There is lack of concern on the discussion of why such formula works. This learning situation commonly happens in Indonesia. This situation may lead students to the lack of understanding of area measurement. This is supported by study stating that the lack of understanding of mathematical concepts is due to the use of traditional teaching methods in which formulas and algorithms are more stressed without attention to students' comprehension of the concepts [6]. Moreover, the teaching and learning of area measurement always indicate the lack of concern on the area units. Therefore, the Indonesian students still have a problem in making sense of the area measurement.

Based on this situation, the need to construct an understanding of area measurement through the area unit becomes important. Reference [7] implies that the activity better to provide students to grasp the area is doing covering activity by a particular unit. While measuring area by the covering activity, several concepts underlying the unit of area in area measurement are triggered. Some of them are the idea of unit consistency and the inverse relationship. Unit consistency implies the use of identical unit to cover region to obtain the area. This is important concept since the students still have a problem when reporting the number of some nonidentical units used while covering. They count the total number of larger and smaller units as the single amount representing the area. Meanwhile, inverse relationship means the opposite relationship between the number of the unit used and the size of the unit chosen while covering.

Therefore, this study concerns on the area unit understanding to help students understand the area measurement. Some covering activities were designed with the use of photo frame context. The aim is to promote students' understanding of the idea of unit consistency and the inverse relationship between area measurement by the use of area unit and the size of the unit used.

Finally, this study looks forward to the answer of following research questions 
1. How does photo frame context lead the pupils to the use of identical units to measure and compare area?

2. How does photo frame context help pupils to understand the inverse relationship between unit size and the number of the unit used to measure area?

\section{METHOD}

\section{A. Research Approach}

The intention of the study was to know how the activities using the photo frame context could help the students to understand the idea of unit consistency and the inverse relationship. Therefore, design research was used as the research approach which consists of preparing for the experiment; the design experiment; and the retrospective analysis [8]. In this study, design research was conducted within two cycles (preliminary teaching experiment/pilot study and teaching experiment). However, this paper only provides the readers with the teaching experiment result (the second cycle) regarding the latest result obtained in this study. The readers are provided with the hypothetical learning trajectory (HLT) designed in teaching experiment including the learning goals, the activities, and the hypothetical students' thinking process [9]. The HLT can be found in Table 1.

\section{B. Data Collection and Data Analysis}

These learning activities were conducted by IRME approach in Elementary School in Surabaya. The research subject was students of third grade that consisted of fifteen students with Rama, Ranti, Raffa, Asti, and Sasi as the focus group, and also the mathematics teacher as the teacher in the experiment. The data of students' activities, students' learning, and students' thinking process obtained from the video recording, students' written work, and interview during the lesson of teaching experiment were used as the sources of the analysis.

The students' work was analyzed and the fragments followed by the transcription from videos that showed students' learning and thinking process were made and analyzed as well. These sources were triangulated each other to support the researcher in conducting the retrospective analysis which is defined as examining the whole data set collected during the teaching experiment [10]. The result of activities was compared to the HLT and was used to revise and improve that initial HLT.

TABLE I. THE HYPOTHETICAL LEARNING TRAJECTORY OF THE STUDY

\begin{tabular}{|l|l|l|}
\hline \multicolumn{1}{|c|}{ Activity } & \multicolumn{1}{|c|}{ Task } & \multicolumn{1}{|c|}{$\begin{array}{l}\text { Conjectured students } \\
\text { thinking and actions }\end{array}$} \\
\hline $\begin{array}{l}\text { Comparing } \\
\text { the frames } \\
\text { part } 1\end{array}$ & $\begin{array}{l}\text { The group of students } \\
\text { compare the frame } \\
\text { directly by the use of } \\
\text { photos (photos } \\
\text { provided are } \\
\text { intentionally made } \\
\text { various in size) }\end{array}$ & $\begin{array}{l}\text { - } \begin{array}{l}\text { Do the superposition } \\
\text { (visual reasoning) }\end{array} \\
\text { - The need of tools to } \\
\text { measure each frame } \\
\text { (photos) to clarify their } \\
\text { decision on which frame is } \\
\text { larger }\end{array}$ \\
& $\begin{array}{l}\text { - Use different sized photos } \\
\text { Report the size of photos } \\
\text { as a number of photos }\end{array}$ \\
\hline
\end{tabular}

\begin{tabular}{|c|c|c|}
\hline $\begin{array}{l}\text { Measuring } \\
\text { the frames }\end{array}$ & $\begin{array}{l}\text { The group of the } \\
\text { students measures the } \\
\text { frames by the use of } \\
\text { photos (photos } \\
\text { provided are } \\
\text { intentionally made } \\
\text { various in size) }\end{array}$ & $\begin{array}{l}\text { - Report the number of } \\
\text { different sized photos used } \\
\text { in a single amount of } \\
\text { number. For example, } \\
\text { reporting the size will be c } \\
\text { (instead of a and b) for the } \\
\text { frame which includes } \\
\text { bigger photos and b smaller } \\
\text { photos where a, b, and c } \\
\text { are the particular number } \\
\text { - Already regard the size in } \\
\text { counting the number of } \\
\text { photos. For example, } \\
\text { reporting the size will be a } \\
\text { and b for the frame which } \\
\text { includes bigger photos and } \\
\text { b smaller photos where a, } \\
\text { b, and c are the particular } \\
\text { number }\end{array}$ \\
\hline $\begin{array}{l}\text { Comparing } \\
\text { frames part } \\
2\end{array}$ & $\begin{array}{l}\text { The students decide } \\
\text { the correct choice of } \\
\text { larger/smaller frames } \\
\text { based on the number } \\
\text { of photos }\end{array}$ & $\begin{array}{l}\text { - The students derive the } \\
\text { idea of identical units to } \\
\text { measure and compare } \\
\text { - The students derive the } \\
\text { inverse relationship }\end{array}$ \\
\hline
\end{tabular}

\section{RESULT AND DISCUSSION}

These activities aim to emerge the understanding of the identical unit (unit consistency) to cover region through the photo frame context and to investigate the relationship between the size of the unit with the number of the unit used to cover the region (inverse relationship). Finally, the students are set to understand the use of identical units to measure and to compare the area of the region.

Firstly, the students were provided with three different frames based on their shape and their size $(6 \times 6,5 \times 7$, and $9 \times 4$ of smaller photos intentionally and consecutively set for each frame) to initiate their thought. Those three different twodimensional objects are provided in Figure 1 below. The teacher showed the frames and asked the students to determine which frame was the largest one. The students were set to firstly get into 'comparison' situation before discussing 'measuring', which was the core of the task.
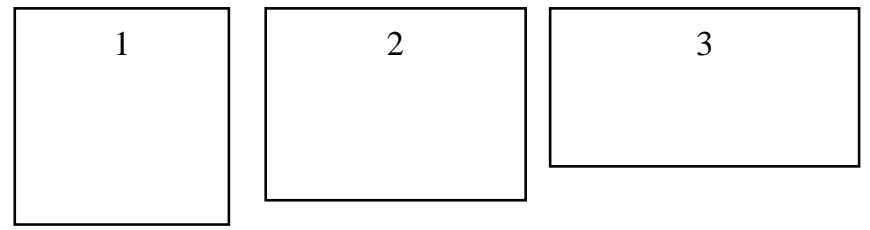

Fig. 1. The frames used in comparing the frames activity part 1

The following conversation displayed the discussion around the first activity (translated in English)

Teacher : Which one is the largest? Give your reason! 
Students : One

(Ranti raises her hand)

Teacher : Okay Ranti

Ranti : One [without giving reason]

Teacher : What about you Rama?

Another pupil is saying two

Teacher : Rama...

(Rama is exploring his fingers to make rectangular figure while his eye looking through the middle of figure to the frames the teacher is holding)

Rama : That's the square [referring to the first frame], the longer one [referring to the second frame] or another one?

Teacher :Which one is the largest Ma?

Rama :One

Teacher :What about you Ais?

Aisya :One

Teacher :One also

Hiu :One

Teacher :One, Sashi?

Sashi :Two

Teacher :Why is it two Sashi?

Sashi : I can see that is larger...

Observer: Show us, can you show us?

Sashi :This part is longer and also that one [she compared the longer side on the second frame with the side of the first frame, and compare another side of the

Teacher :Adhif second frame with the side of the third frame]

\section{Adhif : Number one}

Teacher : Why is it number one?

Adhif : [touching the side of square frame and compare it the side of the second frame] this one is longer than this

Teacher : So, it's longer

Asti : One (showing the same way as Adhif did)

The other students also argued that frame 1 is the largest

The students directly argued which one was the largest through their visual reasoning. Most of them chose the first frame as the largest one. There was no exact superposition (putting one on top other to find which one is larger) they made. In fact, they only argued based on whether the the particular side of the frame was longer than others'. For example, they chose frame one to be the largest one since it has a longer side as what Adhif explained as indicated in Figure 2.

What found next is that some of the students seemed not aware of the lack of their argument. Even though they argued about the sides, they did not seem to take into consideration another possible length of sides (e.g the longer side in frame 3 compared to the side of the first frame). They used only one side of each frame to compare and found which one is larger. It was also assumed that the first frame was treated the largest since for them it looked larger while the other two did not really look larger but longer even though they did not use the longer side of these two frames to compare with the side of the first frame.

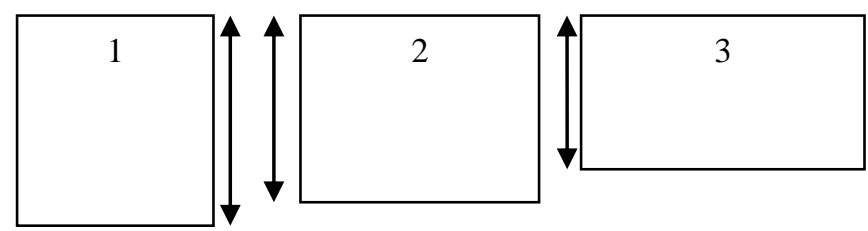

Fig. 2. Comparing the size of the frames by looking at one side

Based on the situation, the teacher moved the students from 'comparing' situation to the 'measuring' situation. The teacher asked the students to convince themselves by measuring the size of each frame to really prove their answers were correct. It was observed that the students shifted successfully from 'comparing' situation to 'measuring' situation and they knew already what they were doing. They needed to find the size/area of each frame by the use of photos and determine the order of frame.

\section{A. Measuring the Frame}

The teacher distributed the frame and bunch of photos for each group. The students were intentionally provided different sized photos to see whether the students mix up the photos that need to be attached to the frame. In fact, it was found that the students did mixing up while observation on each group's work was being conducted. Each group used those two different sized photos on their frames as seen in Figure 3.

Before the class discussion, the students accomplished the questions on the worksheet about the frame they made. The following Figure 4 showcases the representative of the answer of each group.

It was found that the students in these two groups responded the question "How many photos are used to cover the frame?" with an appropriate interpretation by counting both different sized photos to get a particular number. They treated those different sized photos the same in the process of counting the number of photos used. Tita's group used 17 photos on the frame consisting 6 larger photos and 11 smaller photos while Ersa's group attached 21 photos consisting 5 larger photos and 16 smaller ones.

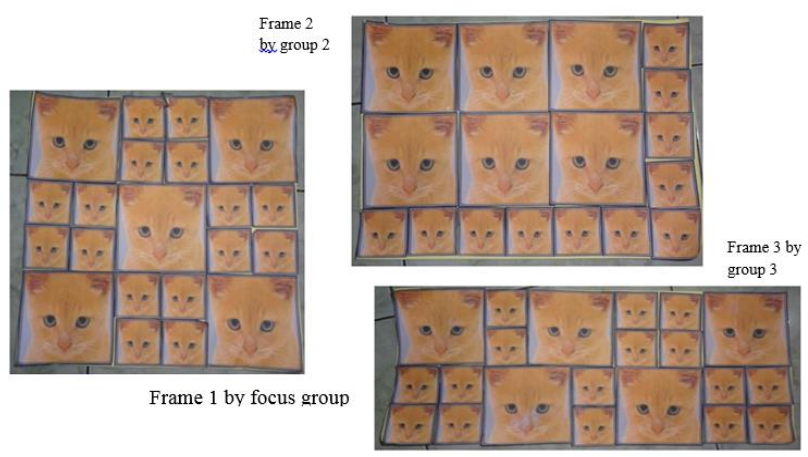

Fig. 3. Groups' works on frame 

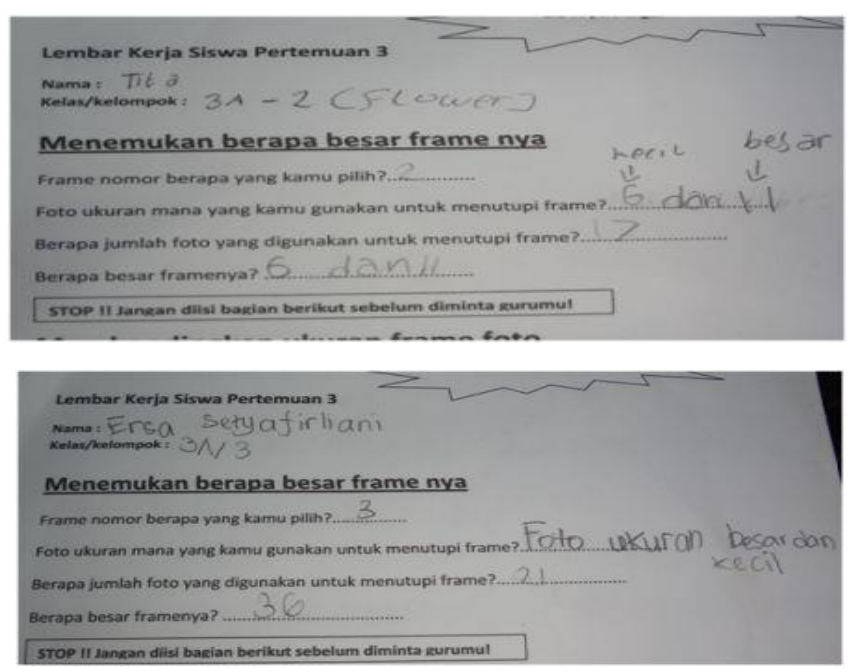

Fig. 4. The groups' answers to the questions of the worksheet

When the question moved to find the size of their frame, these both groups came with the idea of a number of photos as the size of the frame and they got a different idea in expressing their frame size. Tita's group expressed the size of the frame by the use of those both different sized photos (6 and 11) while Ersa's group obtained 36 as the size of their frame. The interpretation that can be drawn is that Ersa's group came with an idea to express the size of the frame by the use of only smaller photos. This situation entails that Ersa's group treated larger photos as four smaller photos since they could see that four smaller photos could occupy one larger photo. Then they used those ideas to find the size of the frame. Hence, it is assumed at this phase that they started to derive the idea of the identical unit to measure the area.

In the focus group of the study, it was found that the students interpreted the question about the number of photos used adequately. They used 21 photos consisting 5 larger photos and 16 smaller ones. However, a pupil named Rama had different answer amongst other in his group about the question of the size of the frame. Overall, the students in our focus group did not yet derive the idea of the identical unit in this task.
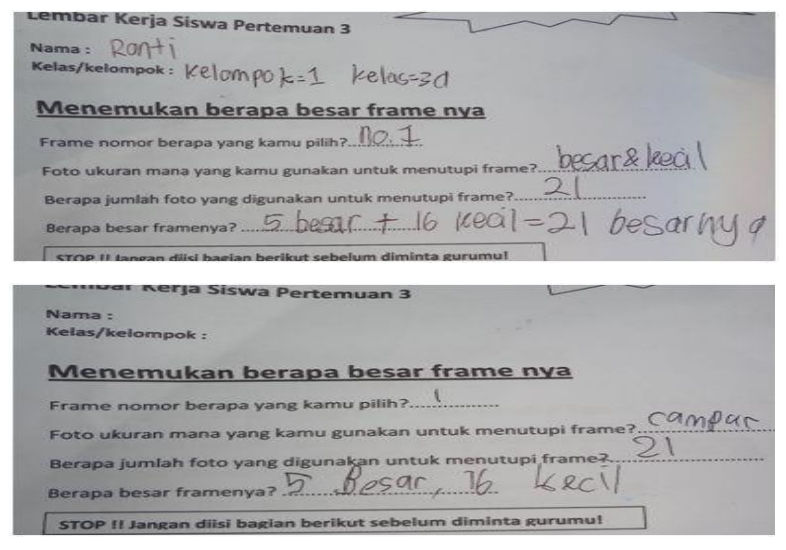

Fig. 5. Focus groups' answers to the questions of the worksheet
Ranti, Raffa, Sasi, and Asti expressed the size of the frame to be ' 5 larger +16 smaller $=21$ '. It is clear that they already considered the number of each larger and smaller photos in this measuring area task at the beginning. However, the addition operation summing up the total photos (larger and smaller) to get 21 as the size of the frame implied something else. It indicated that they finally treated 21 as the size of the frame in which they ignored the fact that both photos have different size so that summing up the number is not appropriate to do to express the size of the frame. It is derived based on this fact that they would get another size, for example, 15, as the size of the frame which contains 12 smaller photos and 3 larger ones. Based on this analysis, it is concluded that these students could not yet express the area in how many units $\boldsymbol{a}$ is used and $\boldsymbol{b}$ is used if $\boldsymbol{a}$ and $\boldsymbol{b}$ are differently. They instead treated the sum of $\boldsymbol{a}$ and $\boldsymbol{b}$, let say $\boldsymbol{c}$, to be the area.

Rama, in his own way, responded to the 'size' question with an answer of 5 larger photos, 16 smaller ones as the size of the frame. He did not at all sum up the number of photos. It implies that he knew that both photos are different in size so that summing up the number of each is inadequate to do. Hence, he just left the size to be 5 larger photos, 16 smaller ones instead. Such conjecture can be proposed, for another case, he would probably not sum $\boldsymbol{a}$ and $\boldsymbol{b}$ to get $c$ as the area if $a$ and $b$ are not the same. He left $\boldsymbol{a}$ and $\boldsymbol{b}$ to be the area. During the group discussion, it was observed that Rama did not do so much discussion with others. Rather, he just listened and sometimes complained about other's opinion but he did not give his idea directly to them. That is why that his answer was by his own way was different with other students in his group.

Nevertheless, it was found that the students in focus group did not yet reveal the idea of the identical unit in this task. They might not yet derive the connection between larger and smaller photos or at least they seemingly ignored this connection. That was why we assume that they could not yet express the size of the frame by the use of identical photos, for example, their frame size to be 36 smaller photos.

\section{B. Comparing the Frames}

The students went back to the initial problem about determining which frame was the largest. The students would also come with the order of the frame based on the size. During the group discussion, it was found that students came with the right order of the frame based on the size and determined the largest frame which was frame 1 and 3 by group 1 and 3 respectively. It is noted that the group came with a different way of a solution. The level of the solution was also different.

It was remarkable that the solution of Ersa's group was based on the idea of the identical unit, measuring the frame by the use of only smaller photos even though they used both photos. The following is the conversation between observer and Ersa's group

Observer :To be able to compare each frame, what is it supposed to be? How is the size of the photos?

Olga : Count the photos, the larger photo is counted four. 
Observer : The larger photo is counted four, then?

Olga : The smaller one is counted one

Observer : Counted one, then you get which one is the larger and smaller? [Referring to the frame]. Do you understand what Olga said?

(Ersa nods her head implying that she agrees with Olga's statement)

Observer : Hiu, do you understand what Olga said?

Hiu : No

Observer : Olga...Olga can you explain again your opinion?

Olga : Let's Esa do it

Ersa $\quad$ : I think it is better to use just smaller photos or just larger photos

Observer : Okay

Observer : Okay Hiu, what is the way to make the frame comparable?

Hiu : Yes. The larger one is counted four, the smaller one is counted one.

It was assumed that they thought that it would be fair to compare the frame if they counted only one type of photo which was the smaller photos they chose. By counting the larger as four smaller photos, they would express all the frame size in term of smaller photos, so that the result of counting would enable them to compare the size of those frames. They got frame 1 and 3 as the largest and both frame were the same size, 36 smaller photos and then frame 2 with 35 smaller photos. Based on this situation, it was concluded that this group used the idea of identical photos to compare the frame. Hence, they already moved to the next level of understanding, from the use identical photos to measure the frame to the use of identical photos to compare the frame.

The other groups, Tita's group and the focus group had seemingly the same solution into the frame comparison. Tita's group argued that both frame 1 and 3 as the same and the largest ones. It was found that they decided 1 and 3 because both frames had the same number of photos which was 21 photos (both for larger and smaller ones) while frame 2 they made only consisted 17 photos (for both smaller and larger ones). It was assumed that both frames, 1 and 3 which contained the same number of larger and smaller photos (5 and 16 respectively) might give the insight to them that both frames had the same size and they both were the largest ones.

The following was a conversation between students in focus group during this section.

Observer : How is the size of photos in each frame so that you can compare them?

Asti : Same

Observer : In that situation, each frame contains mixed photos, can you compare them?

Asti : We can

Raffa : Different

Observer : Different? Okay, if they are different, can you compare them?
Raffa : Yes we can. Look at the larger and smaller ones

[Referring to a number of each photo].

At first, Asti seemingly tried to regard the use of the same photos on each frame. However, she then did not go back to it when asked whether they could compare each frame if each had different sized photos on it. She argued that the comparison still could be done in that circumstance. Her opinion implied that she just left her potential idea on the use of the identical photos as she stated before. In addition, her latest opinion was supported by Raffa's argument that the comparison was still conductible by considering the number of each smaller and larger photos on each frame. Since the frame 1 they made and the frame 3 the Ersa's group made contained the same number of photos, 21 (for both smaller and larger one) and each frame even contained the same number of larger and smaller photos (5 and 16 respectively), they concluded that the frame was the same size and both were the largest.

The interpretation towards the situation is drawn based on a focus group that this group might not yet reveal or might not yet regard the idea of identical photos to do a comparison. In respect to this situation, frame 1 and 3, their way might be true. However, it was conjectured that their strategy will probably no longer be applicable if both frames contain a different number of smaller and larger photos. They might think to step further. They might figure out another way to compare the frame size. It is also conjectured that a little guidance given to this group might trigger Asti to recall her idea about the use of identical photos she just stated. It is assumed that this group will be helped as like Ersa's group if they work the idea of identical photos out.

\section{Class Discussion}

The teacher headed the discussion. She tried to bring the students to the idea of the identical unit to help them to compare the frame size.

Teacher : How is our way so we can count them all, all larger or just all small?

Students : The photos should be the same

Teacher : Yes, the photos should be the same. What if the larger photos replaced by the smaller ones? Can we do that?

Rama : We can

Students : We can

Students in group focus: Yes we can, we need four

Teacher : Yes we need 4. 1, 2, 3, and 4 [putting smaller photos on the one larger photo]. What if we replace all the larger photos on this frame with the smaller ones? So which one of you who already found the number of photos on this frame? [Referring to the first frame].

Bunga : 21

Ranti :21

Teacher : Ersa, what did your group find if we use smaller photos?

Ersa $: 36$

Teacher : What about Ranti's group? 
Ranti :Wait ma'am [counting].

Asti : 36 [smiling].

Observer : What if I ask you about the size of frame 1?

Bunga : 36

Teacher : Frame 2?

Observer : What is the size of frame 2?

Teacher : The way is just the same, replace the larger with smaller ones

Ersa's group: 35

Teacher : What about frame 3?

Some students move in front of the board to count the photos in frame 3

Rama : $: 36$

Bunga : 36 Ma'am

Observer : Okay pay attention, please. So what is the area of this frame? [Referring to the first frame].

Students : 36

Observer : What if I change the smaller ones in this frame with the larger photos?

Ranti : Yes we can, so there are 9 photos there

Observer : So, how many ways do we have to find the area of this frame?

Students : Two, by using the larger photos or smaller ones. If we use smaller ones, it will be 36 and we use the larger ones, it will be 9

From the conversation, it can be seen that some students, especially students coming not from Ersa's group finally realized that they could change the larger with smaller ones, so they only had smaller photos in the frames. These students were brought by the teacher to the idea of an identical unit. It was found that these students finally understood that they could compare the use of identical photos. Especially focus group students, Asti, who finally realized that her idea about using the same photos could be used in this comparison of the frames. She showed that she got the better way to compare the frame which was by the use of identical photos, smaller photos.

It was also found that the students, especially focus group, Rama, Ranti, and others could express the size of the frame more than one way depending on the photos they used. They could use the larger one so that they get 9 . Using the smaller ones gave them 36. It is interpreted that the students could see that the size depended on the photos they use. It is assumed that they understand why the area by the use of larger photos is smaller than the area of the use of smaller photos. It can be concluded that the focus group understands the idea of an inverse relationship.

Based on this analysis, conclusions are drawn.

1. The students understand the idea of identical units to measure and to compare area
2. The students understand the idea of inverse relationship between the size of the units and the area

\section{CONCLUSION}

It is noted that the pupils doing photo frame measurement finally derived the idea of comparing the area by the use of identical units. From that moment on, the pupils had already realized the idea of the identical unit not only to measure but also to compare the area. Hence, the photo frame context could help the pupils to derive the use of identical unit to measure and to compare area.

Having understood the use of identical units not only to measure but also to compare area, the pupils started to realize that the different result by the use different unit occurred when they measured the same frame. It was observed that the pupils tried to make the connection between the size of the unit used with the number of units used to cover the surface. It can be interpreted that the pupils made the inverse relation between the unit size and the number of units. This relationship was seemingly understood by all the pupils. Therefore, it is concluded that the photo frame context could help the pupils to understand the idea of the inverse relationship between the unit and the area.

\section{REFERENCES}

[1] D. Haris, I. Puri, and R. Ilma, "The role of context in third graders' learning of area measurement," IndoMS JME, vol. 2, no. 1, pp. 55-66, 2011.

[2] M. Cavanagh, "Year 7 students' understanding of area measurement," Aust. Assoc. Math. Teach. Inc, p. 136, 2007.

[3] K. Zacharos, "Prevailing educational practices for area measurement and students' failure in measuring areas," J. Math. Behav., vol. 25, no. 3, pp. 224-239, 2006.

[4] E. Nitaback and R. Lehrer, "Developing spatial sense through area measurement," Teach. Child. Math., vol. 2, no. 8, pp. 473-477, 1996.

[5] Febrian, "Educational Design Research: Developing Students' Understanding of Area Measurement through the Unit of Area," Surabaya State University; Utrecht University, Indonesia, The Netherlands, 2013.

[6] K. Zacharos and D. Chassapis, "Teaching suggestions for the measurement of area in Elementary School. Measurement tools and measurement strategies," Rev. Sci. Math. ICT Educ., vol. 6, no. 2, pp. 41-62, 2012.

[7] R. Lehrer, L. Jaslow, and C. Curtis, "Developing an understanding of measurement in the elementary grades," Learn. Teach. Meas., vol. 1, pp. 100-121, 2003.

[8] A. Bakker and D. van Eerde, "An introduction to design-based research with an example from statistics education," in Approaches to qualitative research in mathematics education, Springer, 2015, pp. 429-466.

[9] M. A. Simon and R. Tzur, "Explicating the role of mathematical tasks in conceptual learning: An elaboration of the hypothetical learning trajectory," Math. Think. Learn., vol. 6, no. 2, pp. 91-104, 2004.

[10] K. Gravemeijer and P. Cobb, "Design research from a learning design perspective," Educ. Des. Res., pp. 17-51, 2006. 